\title{
WELL-BEING OF HAEMOPHILIA PATIENTS: A MODEL FOR DIRECT AND INDIRECT EFFECTS OF MEDICAL PARAMETERS ON THE PHYSICAL AND PSYCHOSOCIAL FUNCTIONING
}

\section{A. H. M. TRIEMSTRA, ${ }^{1,2 *}$ H. M. VAN DER PLOEG, ${ }^{1}$ C. SMIT, E. BRIËT, ${ }^{4}$} H. J. ADÈR ${ }^{5}$ and F. R. ROSENDAAL

'Department of Medical Psychology, Vrije Universiteit, Amsterdam, The Netherlands, 'Department of Social Medicine, Academic Medical Center, University of Amsterdam, Meibergdreef 15, 1105 AZ Amsterdam, The Netherlands, NNetherlands Haemophilia Society, Badhoevedorp, The Netherlands, ${ }^{4}$ Department of Internal Medicine, Academic Medical Center, University of Amsterdam, Meibergdreef 15, $1105 \mathrm{AZ}$ Amsterdam, The Netherlands, 'Department of Epidemiology and Biostatistics and the Institute for Research in Extramural Medicine (EMGO Institute), Vrije Universiteit, Amsterdam, The Netherlands and "Department of Clinical Epidemiology, University Hospital Leiden, Leiden, The Netherlands

\begin{abstract}
This study outlines the development and evaluation of a structural equation model for establishing the consequences of haemophilia. The hereditary disorder is characterized by a high tendency to haemorrhages, with recurrent bleeding into the joints causing irreversible joint damage. The model is, in general, an attempt to answer the following questions: what is the effect of haemophilia on the wellbeing (i.e. satisfaction, health, somatic complaints and self-esteem) of patients and what is the additional or mediating role of other individual characteristics in this pathway? Disease severity, joint impairment and disability are defined as antecedents of well-being and the mediating roles of appraisal (i.e. the personal evaluation of the disease), health beliefs (i.e. locus of control), psychological characteristics (i.e. anxiety, anger, depression and optimism) and social support are investigated. Psychological variables turned out to be the strongest determinants of well-being and partly mediated the detrimental effect of disability on well-being. The role of appraisal remained somewhat unclear, as no significant relatıonship was established between this personal evaluation of hacmophilia and well-being. Nevertheless, appraisal very well reflected the level of disability. An internal locus of control and favourable psychological characteristics appeared to reduce the perceived seriousness of haemophilia. No evidence was found for social support to act as a mediator between disability and well-being. The perception of support did show moderately strong associations with psychological characteristics (i.e. anxiety and depression) and satisfaction ratings. The study merits further research on quantifying the relationships between clinical parameters and psychosocial outcomes in patients with a chronic disease. (C) 1998 Elsevier Science Ltd. All rights reserved
\end{abstract}

Key words-haemophilia, well-being, disability, psychological characteristics, social support

INTRODUCTION

\section{Haemophilia}

Haemophilia is a hereditary (sex-linked, recessive) bleeding disorder in which a decreased level of clotting factor activity in the blood may lead to spontaneous haemorrhages in muscles and joints. As the gene which causes this disorder is located on the Xchromosome, haemophilia predominantly affects men. Haemophilia may be regarded as a chronic disease often resulting in disability. Recurrent haemorrhages in joints are likely to initiate arthropathy and may lead to chronic joint impairment and concomitant disability. The classification of severity (into severe, moderately severe or mild haemophilia) depends on the remaining level of clotting

*Author for correspondence. activity in the blood. The treatment of haemophilia is focused on diminishing the frequency of haemorrhages and preventing joint impairment. The clotting activity of the blood can be raised at a sufficient level by infusion with factor concentrates. With the introduction of effective treatment methods at the end of the 1960's (the use of clotting factor substrates and the possibility of prophylactic treatment) and then home treatment in the early 1970's, haemophilia became a controllable disorder that ceased to automatically result in severe levels of joint impairment, disablement and early death (Rosendaal et al., 1991; Nilsson et al., 1992; Triemstra et al., 1995).

The consequences of haemophilia have often been studied in the light of social participation, e.g. employment and sick leave (see Lineberger, 1981; Triemstra et al., 1995). In a review on psychosocial 
issues in haemophilia it was concluded that personality traits of individuals with haemophilia did not differ from healthy controls, but depending on the verity of haemophilia, patients may be at increased risk for problems associated with the adjustment to their illness (Bussing and Bennett Johnson, 1992).

No studies on haemophilia have examined rel'vant components of well-being in a comprehensive model. This article presents a model in which aswciations (i.e. linear relationships) between medical parameters, physical functioning, psychological characteristics and indicators of well-being are simIItaneously tested. As justification for the arrangements of variables within the structural model and for interpretation of the observed relationships must be drawn from logical, theoretical arguments 1 Hoyle and Smith, 1994), the general outline of the model will be based on the natural history of haemophilia and on models for studying the disablement process and health-related quality of life. In addition, theories on stress and coping and empirical findings derived from studies in chronically ill patients on well-being or quality of life will serve as al theoretical basis.

\section{('onceptual framework}

The International Classification of Impairments, 1)isabilities and Handicaps (ICIDH, World Health ()rganization, 1980) provides a basis for studying rutcomes of a disease. It distinguishes three levels of health experience: (1) impairment, which refers to -any loss or abnormality of psychological, physiolingical or anatomical structure or function" at the organ level; (2) disability, defined as "any restriction or lack of ability to perform an activity in the manner or within the range considered normal for a liuman being", referring to activities and behaviours and (3) handicap, which concerns the disadvantages experienced by individuals due to their impairments or disabilities at the social level. Similarly, haemophilia can be referred to as a disorder which causes joint damage (the impairment), limitations in conducting daily activities (the disability) and changes in social functioning or occupying social roles (i.e. handicap).

Disablement models (see Verbrugge and Jette, 1994), which are based on the ICIDH classification, un be extended in order to study quality of life or "ell-being in patients with a chronic condition. In this study, such a "health-related quality of life model" (e.g. Wilson and Cleary, 1995) will be used II evaluate the consequences of haemophilia. As a \!nonym of "quality of life", we will define "wellhing" as a general outcome measure. The basis for lhe conceptual model becomes: haemophilia $\rightarrow$ joint impairment $\rightarrow$ disability $\rightarrow$ well-being. This frame" ork for the research model will be extended with cuncepts which are derived from theories on stress and coping and empirical findings on adaptation to chronic diseases.

Well-being is often used as a global outcome in evaluative studies on the quality of adaptation to illness and it can be defined as a reflection of the way patients perceive and react to their health status and to other, nonmedical aspects of their lives (Gill and Feinstein, 1994). In order to establish such an aggregated measure, we will assess wellbeing in terms of satisfaction, general health, somatic complaints and self-esteem.

In theories on stress and coping, subjective wellbeing is suggested as a consequence of coping (Lazarus and Folkman, 1987; Lazarus, 1991). Appraisal has a central role in coping with a disease as it influences the way the disease is perceived and managed (Cohen and Lazarus, 1979). Appraisal includes both a judgement of the situation (e.g. illness) in terms of its significance for the person's well-being (primary appraisal), and an evaluation of resources and options available for coping (secondary appraisal). Examples of resources are health beliefs, social support and personality traits. These resources might facilitate adaptational responses and could result in behavioural adaptation. In accordance with the stress and coping theories, we will assign a central role to appraisal in our model. The personal evaluation of haemophilia is expected to mediate the effect of disability on well-being. Furthermore, health beliefs (health locus of control orientations) and psychological characteristics (i.e. affective traits and optimism) are hypothesized to influence the appraisal of haemophilia. Social support will be depicted as an external coping resource.

Many studies among patients with a chronic illness (e.g. back pain, spinal cord injuries, theumatoid arthritis) documented relationships between patient characteristics and well-being. Parameters that seem to matter in determining one's overall well-being are the self-reported degree of disability, the psychological status (i.e. cognitions, emotions or symptoms) and social factors (e.g. social support). Pain, as a determinant of disability, is particularly likely to undermine the psychological wellbeing as it shows strong associations with depressive symptoms (e.g. Brown, 1990). Psychological factors are often suggested to play a mediating role in the adjustment to a disease. A sense of control or a feeling of competence, low levels of affective traits and dispositional optimism are all reported to favour well-being (e.g. Weinberger et al., 1990; Smith et al., 1991; Schwarzer, 1994). Social support has been hypothesized to benefit well-being directly as well as indirectly by acting as a mediator or a buffer in coping with stress or illness (Lazarus and Folkman, 1984; Cohen and Wills, 1985; Schulz and Decker, 1985). In studying social support, a general distinction must be made between structural and functional characteristics (Cohen and Wills, 1985). The perception of support is suggested to play a 
major role in possible effects of social support. It is also important to study conjointly both positive and negative aspects of social interactions, as problematic aspects (e.g. misunderstanding, conflicts) seem to be more strongly linked to psychological well-being than positive support (Revenson et al., 1991).

\section{Theoretical model}

Figure 1 presents the model (or path diagram) which we derived from theory. The signs along the unidirectional arrows (i.e. paths, connecting latent constructs) indicate whether a positive or a negative influence is expected. The latent variables are represented by ellipses and these hypothetical constructs are indicated by measured variables (in boxes). As can be seen from Fig. 1, the model encompasses a few contentions. First of all, the severity of haemophilia is hypothesized to have a detrimental effect on well-being via increased levels of joint impairment and disability. The effects of joint impairment and its concomitant disability summate over time and influence the satisfaction with life, health and self-esteem. Secondly, it is expected that appraisal, psychological characteristics and social support mediate the effects of haemophilia on well-being, and that health beliefs (i.e. health locus of control orientations) mediate the effects of disability on the personal evaluation of haemophilia (i.e. appraisal). A high level of disabilty is hypothesized to undermine one's sense of control (i.e. an internal orientation) and a favourable psychological status. Also, psychological characteristics will influence appraisal, social support and overall well-being. Finally, we expect age to have a direct effect on the level of joint impairment, the degree of ADL-dependency, health beliefs and health status (i.e. perceived health and somatic complaints).

\section{METHODS}

\section{Patients and procedures}

Data for this study were collected in 1992 among haemophilia patients in the Netherlands. Pre-structured questionnaires were sent to all haemophilia patients known to physicians of haemophilia treatment centres and the Netherlands Haemophilia Society. The questionnaire contained several items on medical and psychosocial aspects related to haemophilia as well as standardized psychological scales. Of the 1,263 patients who were asked to participate, $980(78 \%)$ completed and returned the questionnaire by mail (in a prepaid envelope).

Only males with haemophilia who completed the questionnaire independently were included in this study. In all other cases, young age or serious comorbidity (e.g. spinal cord injury, stroke, dementia or schizophrenia) hindered patients from complet- ing the questionnaire by themselves (so someone else finished it for them). Of the 980 completed questionnaires, 763 were completed by patients themselves and these cases showed to be at least 15 years of age. Furthermore, 52 respondents who were infected with HIV were excluded from analyses, since having HIV was considered to have specific effects on well-being which were beyond the focus of this study. A total of 711 patients were eligible for inclusion in this study.

\section{Measurements}

Severity of haemophilia. The classification of severity of haemophilia referred to the laboratory diagnosis obtained from physicians. Three levels of severity are distinguished, depending on the residual clotting factor (VIII or IX) concentration in the blood: $1=$ mild haemophilia $(5-40 \%$ clotting factor activity); $2=$ moderately severe haemophilia $(1-5 \%) ; 3=$ severe haemophilia (less than $1 \%$ of the normal activity). In addition, subjects were asked to record the frequency of haemorrhages for the year (1991) preceding the questionnaire survey.

Impairment. The sum score of a 16-item scale was used to reflect joint impairment. Scores were obtained for ankles, the back, elbows, fingers and hands, hips, knees, the neck, shoulders and wrists. A 4-point answering format was used ("no impairment at all" to "severe impairment").

Disability. An activities of daily living (ADL) index, which was highly comparable with the OECD indicator for long term disability (McWinnie, 1982), was used to express the degree of functional impairment. The index contained self-care tasks (e.g. dressing), domestic activities (e.g. climbing stairs) and outdoor activities (e.g. shopping, walking long distances). Patients were asked to rate 9 activities on a 5-point scale of dependency: 1 = without difficulty; 2 = with some difficulty; $3=$ with much difficulty; $4=$ only with assistance; $5=$ does not perform, total dependency. A total score was computed with a possible range of 9 to 45. Low scores indicated a low degree of functional impairment, while high scores referred to a high level of disability and dependency. The scale proved to have a high internal consistency (Cronbach's $\alpha=0.93$ ). Pain, as a second indicator of disability, was measured with one item on how frequent patients suffered from pain due to haemophilia (5point answering format, ranging from "never" to "very often").

Appraisal. The personal evaluation of haemophilia and its consequences was assessed by addressing the following questions: "How do you perceive your haemophilia?" (with a 5-point response scale, "not serious at all" to "a very serious disorder") and "to what extent are you restricted by haemophilia in your daily activities?" (with a 3-point answering format, "no restraints" to "strong impediment"). 


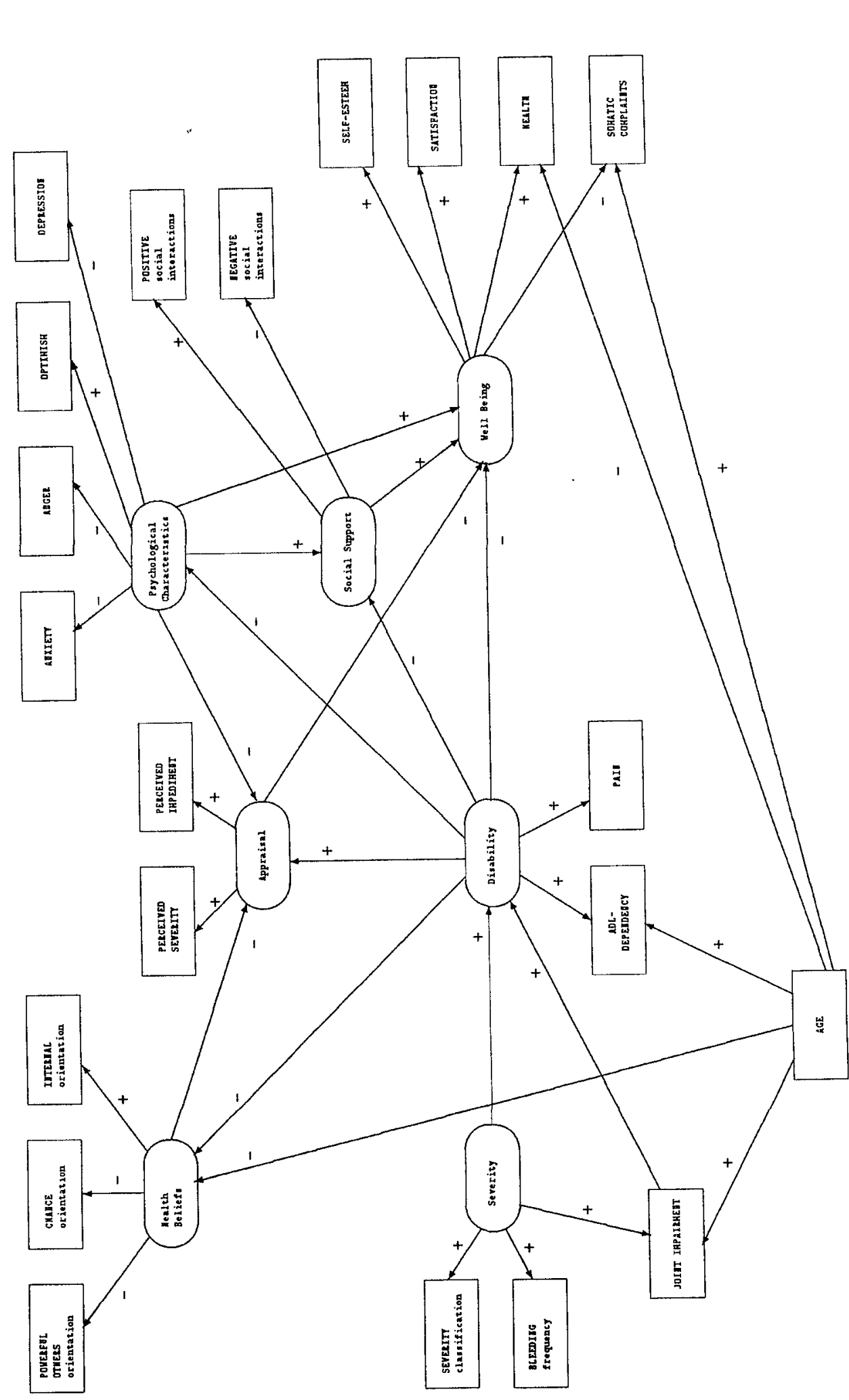


Health beliefs. The Multidimensional Health Locus of Control (MHLC) scale was used to measure the degree to which people percelve themselves as having control over their own health. Two Dutch versions of the scale (Jonkers, 1986; Halfens and Philipsen, 1988) were adapted to obtain one close equivalent of the original scale of Wallston et al. (1978). The scale consists of three dimensions: internal (the extent to which individuals perceive their own behaviour as responsible for their health), powerful others (the extent to which individuals perceive powerful relevant other people, e.g. their physician, as responsible for their health) and chance (the extent to which individuals perceive luck, fate, or chance as responsible for their health). Each subscale consists of six items and the answering format was a 6-point Likert-type scale ("completely agree" to "completely disagree"). For each subscale a total score was computed, with high scores indicating strong orientations. The internal consistencies of the three subscales in this study were satisfactory (Cronbach's $\alpha$ was, respectively, $0.78,0.73$ and 0.69 ).

Psychological characteristics. Four psychological characteristics were assessed with standardized scales derived from the Dutch Self-Assessment Questionnaire (Van der Ploeg, 1989): anxiety (20 items), anger (10 items), depression (20 items) and optımism ( 8 items). The four scales represent adaptations of Spielberger's Trait Anxiety Inventory (Van der Ploeg et al., 1980; Spielberger, 1983), the Trait Anger Scale (Van der Ploeg et al., 1982; Spielberger et al., 1983), Zung's Self-rating Depression Scale (Zung, 1965; Mook et al., 1989) and the Life Orientation Test (LOT, Scheler and Carver, 1987). Subjects were asked to rate themselves on a 4-point scale of frequency ("almost never" to "almost always"). Sum scores were computed, with low scores indicating a favourable psychological status. Validity and reliability estimates for the four Dutch scales have been documented and reported to be satisfactory or good (Van der Ploeg et al., 1980, 1982; Mook et al., 1989). Cronbachs' $\alpha$ 's in this study ranged between 0.83 and 0.92 .

Social support. The social experiences checklist (SEC) was used to measure perceived support in terms of positive and negative experiences in social interactions (Tempelaar et al., 1987; Van Oostrom et al., 1995). This list is partly based on the social support questionnaire of Revenson et al. (1983). Subjects were asked to rate positive and negative experiences that occurred in the preceding week. Seven positive experiences referred to social interactions that provided support (i.e. emotional, affirmative, instrumental) and eight items described interactions that were perceived as non-supportive (e.g. misunderstanding). The answering format was a 4-point frequency index running from "never" to "often". In this study the reliability of both subscales was good (Cronbach's $\alpha=0.80$ ).
Well-being. Global life satisfaction was established with an 8-item index which was based on a selection of "social indicators of well-being" by Andrews and Withey (1976). The index included "satisfaction with life in general" and satisfaction with seven life domains: social contacts, leisure, daily activities, financial and social status, physical condition, sleep and friends and acquaintances. The answers referred to the "last week" (5-point format: $1=$ "very satisfied", $5=$ "very unsatisfied"). Before individual sum scores were computed, answers were reversely scored in order to obtain a variable which directly reflected satisfaction (with high scores being favourable). The internal consistency of the 8-item scale appeared to be good (Cronbach's $\alpha=0.79$ ). The patients' health was established with the one item "How is your health overall?" (poor, rather poor, moderate, good, or excellent). A Dutch version of the somatic subscale of the symptom checklist (Derogatis, 1977; Arrindell and Ettema, 1986) was used to assess somatic complaints that were related to feelings of physical dysfunctioning (5-point scale of distress, "not at all" to "extremely"). The scale proved to have a good internal consistency (Arrindell and Ettema, 1986). In this study the Cronbach's $\alpha$ of the scale was 0.81. Furthermore, a Dutch adaptation of Rosenberg's Self Esteem Questionnaire was used to measure a "favourable or unfavourable attitude towards oneself" (Rosenberg, 1965; Sanders, 1977). This 9-item scale measures self-esteem as a unidimensional concept. In this study Cronbach's $\alpha$ of the self-esteem scale was 0.85 .

Demographic variables. Age was hypothesized to have a direct (constant-linear) effect on joint impairment, ADL-dependency, health beliefs, health and somatic complaints. The mechanism by which age affects certain parameters is dualistic. Firstly, impairment and a deterioration of health is likely to occur with increasing age. Secondly, the effect of age might implicitly reflect changes over time in the management of haemophilia (i.e., older patients are more likely to suffer from joint impairment since they did not receive adequate treatment at a young age) and changes in health related cognitions.

\section{ANALYSES}

\section{Handling of missing data}

To enable running analyses on a large common data set, estimation of missing data was required. Although the item non-response for any of the 149 scale items was no more than $12 \%, 344(48 \%)$ of the eligible 711 patients had missing data for at least one of the many variables or scales that were to be included in the analyses. The listwise percent missing was highest for the scales "depression" $(15 \%, \quad N=106), \quad$ "joint impairment" $(15 \%$, 
Table 1. Descriptive measures according to the severity of hemophila (means and standard deviations)

\begin{tabular}{|c|c|c|c|c|}
\hline & Severe $(N=233)$ & Moderate $(N=105)$ & Mild $(N=260)$ & Total $(N=598)$ \\
\hline Age & $36.2(12.1)$ & $37.2(13.6)$ & $38.4(138)$ & $373(13.1)$ \\
\hline Bleeding frequency & $16.3(149)$ & $6.8(9.6)$ & $1.0(3.7)$ & $8.0(12.5)^{\mathrm{a}}$ \\
\hline Joint imparment & $25.8(7.4)$ & $20.6(5.2)$ & $18.7(5.4)$ & $218(7.0)^{\mathrm{d}}$ \\
\hline \multicolumn{5}{|l|}{ Disabilıty } \\
\hline ADL-dependency & $15.9(6.7)$ & $12.3(4.7)$ & $101(2.8)$ & $12.8(5.7)^{\mathrm{d}}$ \\
\hline Pain & $32(0.9)$ & $2.5(1.1)$ & $17(0.9)$ & $2.4(1.2)^{\mathrm{a}}$ \\
\hline \multicolumn{5}{|l|}{ Appraisal } \\
\hline Perceived severity & $2.9(1.1)$ & $2.2(0.9)$ & $1.9(0.9)$ & $1.2(0.4)$ \\
\hline Perceived impediment & $1.9(0.7)$ & $1.5(0.6)$ & $24(1.0)$ & $1.5(0.7)^{1}$ \\
\hline \multicolumn{5}{|l|}{$\begin{array}{l}\text { Psychological } \\
\text { characteristics }\end{array}$} \\
\hline Anxiety & $36.9(10.0)$ & $37.2(94)$ & $34.9(9.6)$ & $36.1(9.8)^{\mathrm{b}}$ \\
\hline Anger & $17.0(5.3)$ & $18.2(6.2)$ & $17.3(5.2)$ & $174(5.5)$ \\
\hline Depression & $35.4(7.0)$ & $35.3(7.1)$ & $344(7.6)$ & $349(7.3)$ \\
\hline Optumism & $22.5(4.3)$ & $23.0(4.7)$ & $23.2(43)$ & $229(4.4)$ \\
\hline \multicolumn{5}{|l|}{ Health locus of control } \\
\hline Internal orientation & $231(5.6)$ & $23.4\left(\begin{array}{ll}5 & 3\end{array}\right)$ & $23.0(50)$ & $23.1(5.3)$ \\
\hline Chance orientation & $18.4(5.6)$ & $19.2(5.2)$ & $18.9(5.4)$ & $18.7(5.4)$ \\
\hline $\begin{array}{l}\text { Powerful others } \\
\text { orientation }\end{array}$ & $14.2(4.6)$ & $15.0(50)$ & $15.0(4.9)$ & $147(4.8)$ \\
\hline \multicolumn{5}{|l|}{ Social Support } \\
\hline $\begin{array}{l}\text { Positive social } \\
\text { interactions }\end{array}$ & $18.4(3.7)$ & $18.3(3.6)$ & $18.1(3.7)$ & $18.3(37)$ \\
\hline $\begin{array}{l}\text { Negative social } \\
\text { interactions }\end{array}$ & $11.5(33)$ & $11.7(3.5)$ & $11.2(3.2)$ & $11.4(3.3)$ \\
\hline \multicolumn{5}{|l|}{ Well-being } \\
\hline Satisfaction & $29.6(46)$ & $30.8(4.0)$ & $313(4.4)$ & $30.5(4.5)^{6}$ \\
\hline Health & $4.1(0.8)$ & $4.2(0.7)$ & $4.1(0.8)$ & $4.1(0.8)$ \\
\hline Somatic complaunts & $16.0(4.1)$ & $15.9(3.9)$ & $15.9(5.0)$ & $15.9(4.5)$ \\
\hline Self-esteem & $348(57)$ & 35.2 (5 3) & $360(5.2)$ & $354(5.4)^{b}$ \\
\hline
\end{tabular}

"Significant differences across all three severity categories $(P<0.05)$

"Significant difference between "severe" and "mild" $(P<005)$

"Significant differences between "severe" or "moderate" and "mild" $(P<0.05)$

$N=104)$ and "positive social support" $(15 \%$, $N=103$ ).

Missing data estimates were generated by stepwise regression using maximum likelihood estimation with the statistical package BMDP-AM (Dixon, 1988). For each scale, a maximum number of missings was set, depending on the randomness of missing values and criteria per scale. After imputation of missing values, the overall percentage of missings on an item-level was reduced from 6.1 to $4.9 \%$ of all data points. Inspection of the means, standard deviations and correlations revealed that there were no significant differences on the parameters before and after estimation of missing values. After excluding missing data in a listwise fashion, 598 respondents were left over for analyses. In comparison with those 598, the 113 cases who had too much missing data for a subset of variables were significantly older (mean difference $=10.4$ years, $p<0.001$ ) and more often had mild haemophilia $(65 \%$ vs $43 \%)$. These differences were not expected to bias our research findings, since the variables "age" and "severity of haemophilia" were both incorporated into the hypothesized model and differences in age and severity were statistically accounted for in the analyses.

\section{Structural equation modelling}

The formulated theoretical model (Fig. 1) was tested with linear structural equation modelling (EQS, Bentler, 1989). This method compares the estimated (co)variances under the specified model and those actually observed and the specified model might include various relationships which can be simultaneously tested (Hoyle and Smith, 1994). The technique consists of both factor analysis and regression techniques and it permits estimation of models that include multiple mediators and controls for measurement error. Mediation is only the case if an antecedent is both significantly related to the mediator and the outcome variable and if the relationship between an antecedent and an outcome is (partly) explained by the antecedent's effect on the mediator, which, in turn, directly influences the outcome (Baron and Kenny, 1986). There is strong evidence for mediation if a specific relationship between antecedents and outcomes is no longer significant in the presence of a mediator.

The implied model consists of a measurement model and a structural model. The measurement model refers to the relationships between observed and latent variables (i.e. indicators and hypothesized constructs), whereas the structural model consists of relationships between latent variables (with each variable being simultaneously regressed on all variables hypothesized to be causally preceding that variable). The parameters in the model are computed by maximum likelihood estimation.

In order to assess the stability of the specified model, structural modelling was conducted for two samples of data. The study sample had been randomly split into two groups. Each sample consisted 
of 299 haemophilia patients. No signıficant differences appeared to exist between the two samples as to the distribution of severity of haemophilia. Before the full structural equation model was fitted, convergent and discriminant validity of the measurement model was assessed by confirmatory factor analysis as advocated by Anderson and Gerbing (1988) on the first half of the data (i.e. covariance matrix of 299 subjects). Respecification of the model was considered only if discriminant validity of an observed variable was low (i.e. high correlation with dissimilar variables), or if a certain equation or path in the model did not contribute to a better fit. The selection or elimination of paths was evaluated with the Lagrange Multiplier test and the Wald test. After the final model was evaluated on the first data set, it was replicated on the second half of the data set. To evaluate the fit of the model in both samples, the comparative fit index (CFI) was used (Bentler, 1989, 1990). A CFI of at least 0.90 is desirable.

\section{RESULTS}

Table 1 shows means and standard deviations for all scales and single 1tems, according to the severity classification of haemophilia (i.e. severe, moderately severe or mild). Univariate analyses of variance revealed no significant differences for the variables age, anger, depression, optimism, health locus of control, social support, health, somatic complaints and education level. The mean scores for frequency of haemorrhages, joint impairment, ADL-dependency, pain, perceived severity and impediment were significantly different across all categories, with the highest scores in those with severe haemophilia. Those with severe or moderately severe haemophilia had significantly lower satisfactıon ratıngs than those who were mildly affected. Anxiety and self-esteem were the only psychological character1stics that showed significant differences between severity categorles. Patients with severe haemophilia reported, on average, higher anxiety and lower selfesteem in comparison with those with mild haemophilia.

Table 2 presents significant $(p<0.05)$ intercorrelations among all variables. The majority of variables appears to be moderately to strongly interrelated and, in every case, the direction of the relationship (i.e. a positive or negative correlation) is consistent with the specified theoretical model (F1g. 1). The variables joint impairment, ADLdependency, pain and perceived impediment had strong positive intercorrelations $(r>0.50)$. The strongest intercorrelations were found for anxiety, depression, optimism and self-esteem. Health locus of control orientations (internal, powerful others and chance), positive social interactions and education level were relatively unrelated to the other varrables.
However, these simple correlations do not indicate whether the patterns of observed covariation are consistent with the model's hypothesized causal structure. The structural modelling was conducted to find out whether the specified theoretical model was likely to exist, which causal paths are likely to exist and whether some direct relationships are actually mediated. Because of the split-sample mode, the model was consecutively developed and tested on the first half of the data $(N=299)$ and fitted on the second sample $(N=299)$. Results of this analysis are presented in Fig. 2. The figures along the arrows are standardized path coefficients, computed by EQS, which express the strength of the association (range $0-1$ ). The path coefficients for the second data set are presented in parentheses.

Fitting the measurement model on the first data set $(N=299)$ resulted in some adjustments. The following variables or hypothesized paths were dropped, due to low discriminant validity (according to the Lagrange Multıplier test), or because the model could not fit certain paths: "powerful others" locus of control and both dimensions of social support (positive and negative interactions). The orientation at powerful others could not be fitted as an indicator of health beliefs, since it showed a significant association with the psychological construct (whereas the two other indicators of health beliefs seemed to be rather independent from the psychological characteristics). Fitting social support appeared to be problematic; the Lagrange Multiplier test indicated the negative counterpart of social support to be significantly associated with the psychological construct and well-beng. After omitting the indicator "powerful others" and the construct "social support" from the model, the fit of the measurement model was 0.85 .

In fitting the full (measurement and structural) model on the first half of the data, one further adjustment was made in order to obtain a better fit. This change concerned the variable self-esteem, a hypothesized indicator of well-being (path coefficient $=0.76$ ), which showed low discriminant validity with psychological characteristics and, therefore, had little or no unique contribution to the model fit. In fact, removal of this observed variable from the model resulted in an increased fit, from 0.92 to 0.93 . Fitting the final model on the second half of the data $(N=299)$ also resulted in a good fit $(\mathrm{CFI}=0.95)$. The final model and the obtained path coefficients for both data samples are shown in Fig. 2. Respectively, 84 and $90 \%$ of the variance in disability and 83 and $81 \%$ of the varlance in well-being was explained by the model in the two random samples.

Examination of the final model reveals that it is consıstent with the theoretical model (Fig. 1), except for the omission of the social support construct and two indicators (powerful others locus of control and self-esteem). The relationship between appraisal 
A. H. M. Triemstra et al.

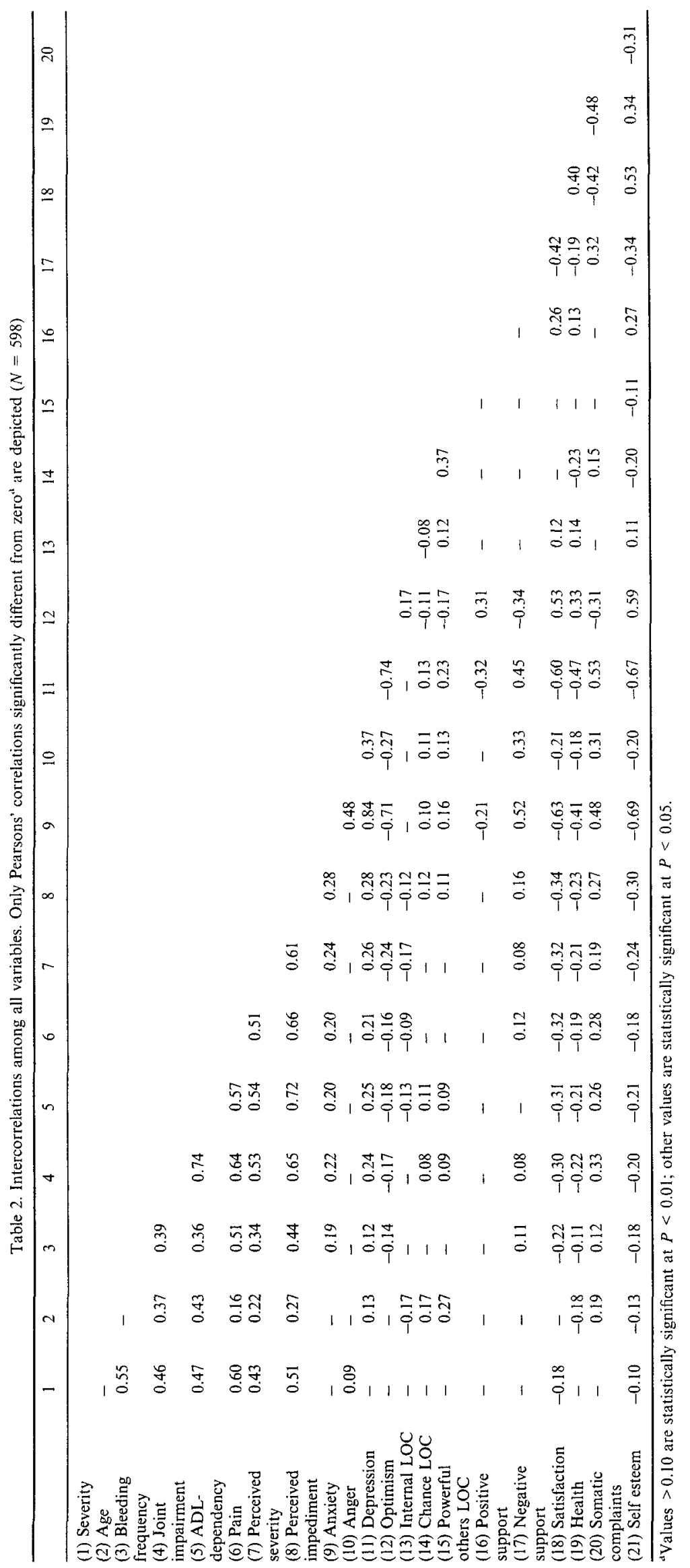




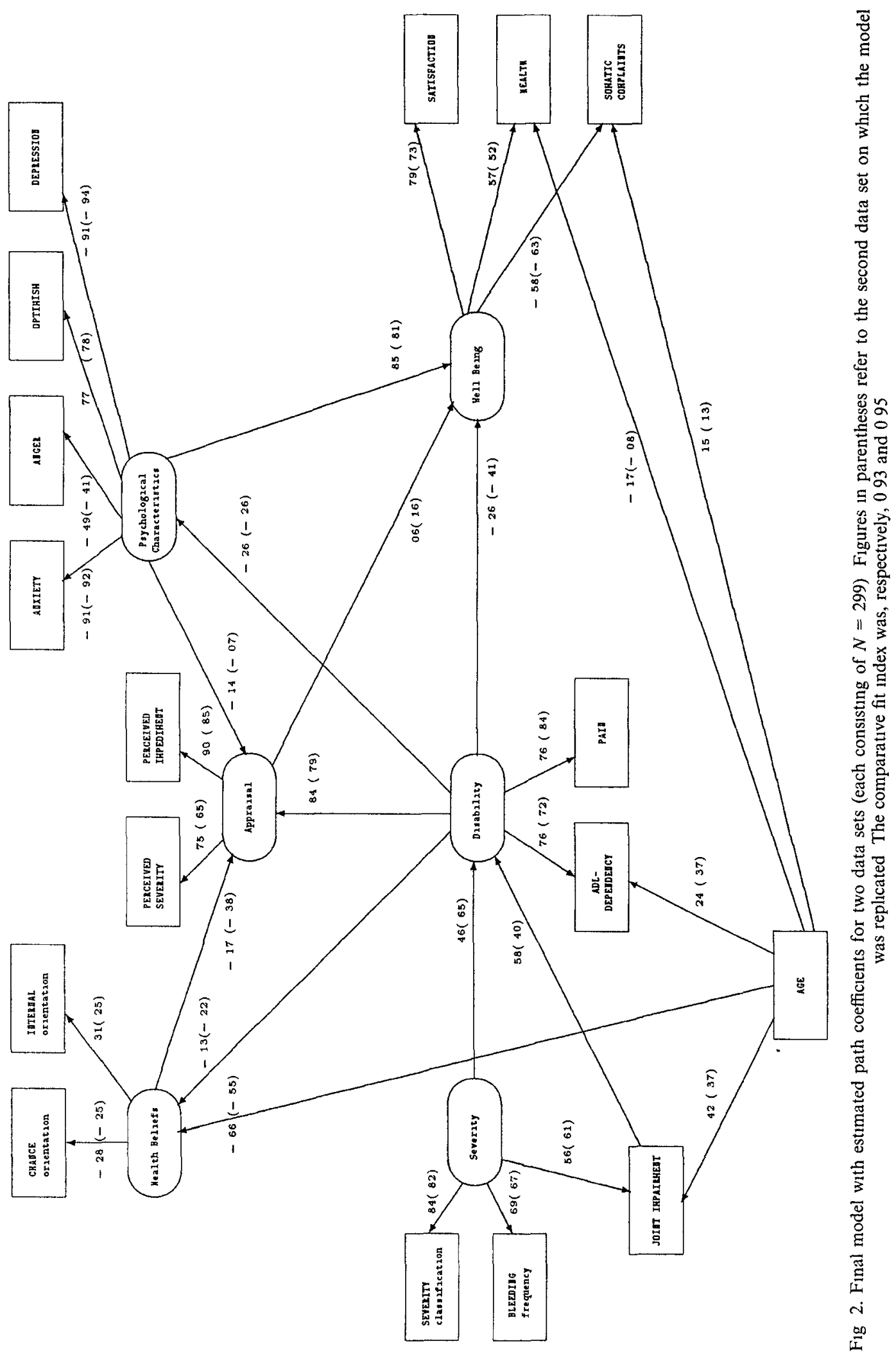


and well-being was insignificant according to the Wald test. Furthermore, according to this test, the existence of significant relationships between psychological characteristics and appraisal, between disability and health beliefs and an effect of age on health was doubtful. Nevertheless, these paths are depicted in Fig. 2, since they were hypothesized in the theoretical model. Comparison of the path coefficients found in the two random samples revealed only a few discrepancies. The largest differences were found with respect to the effect of health beliefs on appraisal and for associations between severity of haemophilia or joint impairment and disability. This indicates that these parameters were not as stable as the other (significant) parameters in the model.

\section{Outline of the final model}

The severity of haemophilia seemed to influence the level of disability directly, as well as indirectly via the development of joint impairment. Age appeared to have a direct relationship with the degree of joint impairment and ADL-dependency. Disability appeared to be very well reflected by the (negative) appraisal of haemophilia. An elevated level of distress (i.e. anxiety, depression, anger) and a reduced feeling of optimism seemed to be concomitant results of functional impairment. Furthermore, disability seemed to affect beliefs regarding health and illness, by reducing the sense of an internal locus of control and reinforcing an orientation to chance. In turn, health beliefs and psychological characteristics show associations with appraisal. Thus, these constructs appeared to act as mediators between disability and appraisal, with a feeling of internal control and favourable scores on psychological characteristics having positive effects on the appraisal of haemophilia (i.e. haemophilia was consequently perceived as a less severe disorder and a lower level of impediment was reported). Age was strongly associated with health beliefs, with older patients reporting less internal control but a stronger belief that chance determines their health.

Well-being showed a strong association with psychological characteristics (average path coefficient $=0.83$ ). Disability appeared to have a detrimental effect on well-being (with a path coefficient between -0.26 and -0.41 ). The total (direct and indirect) effect of disability on well-being was, on average, $-0.46(-0.43$ to -0.49$)$, which was about half the impact of psychological characteristics on well-being. Satisfaction and health ratings showed to be good to moderate indicators of well-being. The perceived general health and somatic complaints were inversely related, with the magnitude of their path coefficients with well-being proving almost similar (respectively, 0.55 and -0.61 ) and both were slightly affected by age.

No significant mediating role of appraisal (between disability and well-being) was established, and the role of social support remained unclear. The omission of the latter construct in the final model can be ascribed to low discriminant validity between social support and psychological characteristics on the one hand and between social support and well-being on the other: Also, fitting social support might have been obstructed by the independent character of both its dimensions $(r=-0.07$, $p=0.08$ ) and, altogether, positive and negative interactions might not have formed a stable construct.

\section{DISCUSSION}

\section{Interpretation and implications}

This study is an attempt to quantify the relationships between clinical parameters and variables expressing the physical and psychological functioning of haemophilia patients. The model used depicted physical parameters and psychological constructs in order to establish their effects on wellbeing. Although the model was tested on cross-sectional data, which hampers conclusions about causality, the final model gives insight into the rather complex nature of relationships that are important in adaptation to illness and it merits further investigation.

The way patients perceive and react to their health status and to other, nonmedical aspects of their lives, showed to be directly influenced by psychological features and the level of disability. Psychological characteristics turned out to be the strongest "predictors" of well-being and they partly mediated the detrimental effect of functional disability on well-being. Disability seemed to have a negative impact on psychological features, particularly on depression and anxiety which were the strongest indicators of the psychological construct. The effect on the level of depression is in line with several studies among patients affected by rheumatoid arthritis (Fitzpatrick et al., 1988; Brown et al., 1989; Revenson and Felton, 1989).

The findings presented in this article stress the importance of preventing (recurrent) haemorrhages to avoid resulting (permanent) joint impairment and disability. Competence to conduct certain life activities (ADL) and the prevalence of pain were both equally well predicted by the severity of haemophilia and the level of joint impairment. Arthropathy and irreversible joint impairment are likely to cause a permanent reduction of mobility and chronic pain. Furthermore, disability could directly result from acute symptoms of haemorrhages (e.g. swelling and pain).

The consequences of haemophilia on a functional level (i.e. disability) are well reflected in the personal evaluation of the disease, i.e. the perceived severity and the perceived level of impediment. Appraisal, therefore, turned out to be a reliable 
construct in which the severity of haemophilia, joint impairment, age and disability were all summed up. Psychological factors appeared to influence the perceived seriousness of haemophilia. The same level of disability seems less debilitating to patients who experience a high internal locus of control, low levels of negative affects (i.e. anxiety, anger and depression) and high optimism. Although a significant association between appraisal and well-being was expected, this relationship was not ascertained by the model. The personal evaluation of haemophilia was perhaps too closely linked to the disability construct to have a mediating effect on well-being. As Lazarus (1991) suggested that appraisal can be referred to as an ongoing feature of well-being, the construct in this study is likely to represent haemophilia-related aspects of well-being.

Our results suggest that patients who feel competent toward maintaning health (i.e. with a high internal health locus of control and a low orientation to chance) evaluate haemophilia as less demanding. This corresponds with studies among patients with rheumatoid arthritis (Smith et al., 1991; Smith and Wallston, 1992), in which a generalized sense of competence contributed to an increased life satisfaction and buffered against depressive symptoms. From other studies it also appeared that patients who strongly believe that they must hold back from doing what they want are more prone to poor psychological adjustment (Turner et al. 1987; Bombardier et al., 1990). Thus, an internal orientation can be viewed as a necessary element in the adjustment to haemophilia, notwithstanding the fact that an orientation to powerful others might also be relevant as it makes patients more amenable to prescriptions, recommendations, suggestions, or assistance by health care providers, family and friends (see Schlenk and Hart, 1984). In conclusion, a treatment situation emphasizing personal control (i.e. self-care approach, encouraging self-responsibility for health) seems to be indicated for the management of haemophilia.

Social support could not be fitted as a mediator between disability and well-being, so the role of this construct remains somewhat unclear. Nevertheless, perceived social support and, in particular, the recent occurrence of negative social interactions, showed to be associated with psychological functioning (e.g. anxiety and depression). Ray (1992) also reported that neither positive nor negative social support was directly related to functional impairment and that the negative component of social support showed a stronger association with anxiety and depression than did positive social support.

\section{Chronicity}

In adaptation to haemophilia, the chronic nature of the disorder might bring about specific problems. It appeared from the final model (Fig. 2) that dis- ability had a detrimental effect on favourable psychological characteristics. A chronic state of disability (together with an increase of age) might undo the positive effect of health beliefs on the appraisal process which, in turn, may have an impact on the management of haemophilia. Similarly, persistent disability is likely to undermine the (positive) effects of the psychological functioning on appraisal, social support and well-being. In the case of social support, a situation in which there is a persistent or even increasing need for support due to disability, might lead to an increased disparity between the need and the actual availability of social support. In the long run, patients might evaluate social interactions as less adequate and it is probably more difficult for them to maintain or establish "need fulfilling" contacts. In general, adaptation to haemophilia must consist of a constant (re-)evaluation of demands and coping resources in order to compensate for the continuing changes in personal and situational factors.

\section{Causality and future research}

Although the findings of this study support the proposed theoretical model, they cannot provide strong evidence for the direction of causal influence due to the cross-sectional nature of the study. The causality implied by the model presented, is based on plausible and theoretical arguments. Part of the causal structure of latent variables is expected to reflect the natural history of haemophilia, while indications for the directionality of relationships between the other (more psychological) constructs stem from theories on coping and empirical findings on adaptation to llness. However, theories on stress and coping underline the dynamic interactions between the situation or stressor encountered and personal factors. Also, empirical data on adaptation to chronic diseases often only reveal associations between the psychological variables of interest, which hampers formulating a causal model. Therefore, the specified relationships between disability, psychological factors and well-being should be considered potentially bidirectional. For example, pain can cause depression and depression can worsen pain (Kellner, 1985) or a low overall level of well-being (i.e. health and self-esteem) can cause depression and anxiety. Nevertheless, by depicting "state" measures as outcomes of the model (i.e. satisfaction and somatic complants referred to the preceding week) and more stable or trait measures as their determinants, we tried to ascertain a causal sequence for psychological factors (health beliefs, appraisal and psychological functioning) in the model and the hypothesized relationships are likely to reflect dominant associations.

We suggest the following research questions to be addressed in future, longitudinal research on adaptation to haemophilia or other chronic diseases: (1) what specific domains of (persistent) disability cause 
changes in well-being?, (2) are psychological factors indeed affected by disability?, (3) can current measures of disease appraisal, health beliefs, psychological characteristics and social support predict well-being in the long run? and (4) what coping strategies contribute to maintaining an internal locus of control and a high level of psychosocial well-being (i.e. physical, psychological and social functioning)? In addition, it would be interesting to study more specifically the influence of coping resources, such as mastery or a sense of control (i.e. controllability of the disease) and the perceived adequacy of social support, in relation to coping behaviour and well-being in patients.

In conclusion, the findings of this study suggest that disability, resulting from haemophilia, has a detrimental effect on the level of well-being. At the same time, psychological factors appear to be of utmost importance in determining outcomes of adaptation to haemophilia. Health beliefs or the controllability of one's health seem to influence the perceived seriousness of haemophilia. The study showed no clear evidence for a mediating role of appraisal and social support in the relationship between disability and well-being. How psychological characteristics and well-being are influenced by the chronicity of disability is also hard to conclude from this study. A longitudinal study, in which both physical and psychosocial parameters are repeatedly measured, will be necessary to evaluate effects of haemophilia on well-being in the long run.

Acknowledgements - The research project was supported by Het Praeventiefonds (No. 28-2139), the Netherlands. We would like to express our gratitude to the participants who completed the extensive questionnaire in 1992 . We also thank the physicians at haemophilia centres and the Dutch Haemophilia Society for their cooperation in contacting patients.

\section{REFERENCES}

Anderson, J. C. and Gerbing, D. W. (1988) Structural equation modeling in practice: $A$ review and recommended two-step approach. Psychological Bulletin $103,411-423$

Andrews, F. M. and Withey, S. B. (1976) Social Indicators of Well-being. Plenum Press, New York.

Arrindell, W. A. and Ettema, J. H. M. (1986) Handleiding Klachtenlijst (SCL-90) [Manual for the Dutch Symptom Checklist (Dutch SCL-90)]. Swets and Zeitlinger, Lisse, The Netherlands.

Baron, R. M. and Kenny, D. A. (1986) The moderatormediator distinction in social-psychological research: Conceptual, strategic and statistical considerations. Journal of Personality and Social Psychology 51, 11731182.

Bentler, P. M. (1989) EQS Structural Equations Program Manual. BMDP Statistical Software, Los Angeles, CA.

Bentler, P. M. (1990) Comparative fit indexes in structural models. Psychological Bulletin 107, 238.

Bombardier, C. H., d'Amico, C. and Jordan, J. S. (1990) The relationship of appraisal and coping to chronic ill- ness adjustment. Behavioural Research and Therapy $\mathbf{2 8}$ 297-304.

Brown, G. K. (1990) A causal analysis of chronic pain and depression. Journal of Abnormal Psychology 99, $127-137$.

Brown, G. K., Wullston, K. A. and Nicassio, P. M. (1989) Social support and depression in rheumatoid arthritis: a one-year prospective study. Journal of Applied Social Psychology 19, 1164-1181.

Bussing, R. and Bennett Johnson, S. (1992) Psychosocial issues in haemophilia before and after the HIV crisis: a review of current research. General Hospital Psychiatry 14, 387-403.

Cohen, F. and Lazarus, R. S. (1979) Coping with the stress of illness. In Health Psychology, eds. G. C. Stone, N. E. Adler and F. Cohen, pp. 216-254. Jossey-Bass, San Francisco.

Cohen, S. and Wills, T. A. (1985) Stress, social support and the buffering hypothesis. Psychological Bulletin 98, 310-357.

Derogatis, L. R. (1977) SCL-90: Administration, scoring and procedures Manual-I for the R(evised) Version. John Hopkins University School of Medicine, Clinical Psychometrics Research Unit, Baltimore.

Dixon, W. J. (1988) BMDP Statistical Software Manual, Vol. 1-2. University of California Press, Berkeley, CA.

Fitzpatrick, R., Newman, S. and Lamb, R. et al. (1988) Social relationships and psychological well-being in rheumatoid arthritis. Social Science and Medicine 27, 399-403.

Gill, T. M. and Feinstein, A. R. (1994) A critical appraisal of the quality-of-life measurements. Journal of the American Medical Association 272, 619-626.

Halfens, R. and Philipsen, H. (1988) Een gezondheidsspecifieke beheersingsoriëntatie-schaal: validiteit en betrouwbaarheid van de MHLC [A health-specific locus of control scale: validity and reliability of the MHLC]. Tijdschrift voor Sociale Gezondheidszorg 66, 399-403.

Hoyle, R. H. and Smith, G. T. (1994) Formulating clinical research hypotheses as structural equation models: a conceptual overview. Journal of Consulting and Clinical Psychology 62, 429-440.

Jonkers, R. (1986) Publieksvoorlichting over borstkanker en zelfonderzoek. Proefschrift. [Public education on breast cancer and self-examination. Thesis]. Maastricht, The Netherlands.

Kellner, R. (1985) Functional somatic symptoms and hypochondriasis. Archives of General Psychiatry 42, 821-833.

Lazarus, R. S. (1991) Emotion and Adaptation. Oxford University Press, New York.

Lazarus, R. S. and Folkman, S. (1984) Stress, Appraisal and Coping. Springer, New York.

Lazarus, R. S. and Folkman, S. (1987) Transactional theory on emotions and coping. European Journal of Personality 1, 141-169.

Lineberger, H. P. (1981) Social characteristics of a hemophilia clinic population: A survey and literature review. General Hospital Psychiatry 3, 157.

McWinnie, J. R. (1982) Measuring Disability. OECD Social Indicators Programme, Special studies No. 5, p. 44. OECD, Paris.

Mook, J., Kleijn, W. Chr. and Van der Ploeg, H. M. (1989) Depressiviteit als dispositie gemeten met de Zung-schaal; interne structuur en relaties met angst, boosheid, coping en sociale steun [Depression as a trait, measured with the Zung-scale; internal structure and relations with anxiety, anger, coping and social support]. Nederlands Tijdschrift voor Psychologie 44, 328-340.

Nilsson, I. M., Berntorp, E. and Löfqvist, T. et al. (1992) Twenty-five years experience of prophylactic treatment in severe haemophilia A and B. Journal of Internal Medicine 232, 25-32. 
Ray, C. (1992) Positive and negative social support in a chronic illness. Psychological Reports 71, 977-978.

Revenson, T. A. and Felton, B. J. (1989) Disability and coping as predictors of psychological adjustment to rheumatoid arthritis. Journal of Consulting and Clinical Psychology 57, 344-348.

Revenson, T. A., Schiaffino, K. M. and Majerovitz, S. D. et al. (1991) Social support as a double-edged sword: the relation of positive and problematic support to depression among rheumatoid arthritis patients. Social Science and Medicine 33, 807-813.

Revenson, T. A., Wollman, C. A. and Felton, B. J. (1983) Social support as stress buffers for adult cancer patients. Psychosomatic Medicine 45, 321-331.

Rosenberg, M. (1965) The measurement of self-esteem: Society and the adolescent self-image. Princeton University Press, Princeton, New York.

Rosendaal, F. R., Smit, C. and Briët, E. (1991) Hemophilia treatment in historical perspective. A review of medical and social developments. Annals of Hematology 62, 5-15.

Sanders, G. (1977) Het Gewone en het Bijzondere van de Homoseksuele Leefsituatie [The Common and Unique Aspects of the Lives of Homosexuals]. Van Loghum Slaterus, Deventer.

Scheser, M. F. and Carver, C. S. (1987) Dispositional optimism and physical well-being: the influence of generalrzed outcome expectancies on health. Journal of Personality 55, 169.

Schlenk, E. A. and Hart, L. K. (1984) Relationship between health locus of control, health value and socia support and compliance of persons with diabetes mellitus. Diabetes Care 7, 566-574.

Schulz, R. and Decker, S. (1985) Long-term adjustment to physical disability; the role of social support, perceived control and self-blame. Journal of Personality and Social Psychology 48, 1162-1172.

Schwarzer, R. (1994) Optimısm, vulnerability, and selfbeliefs as health related cognitions: A systematic overview. Psychology and Health 9, 161-180.

Smith, C. A., Dobbins, C. J. and Wallston, K. A. (1991) The mediational role of perceived competence in psychological adjustment to rheumatoid arthritis. Journal of Applied Social Psychology 21, 1218-1247.

Smith, C. A. and Wallston, K. A. (1992) Adaptation in patients with chronic rheumatoid arthritis: application of a general model. Health Psychology 11, 151-162.

Spielberger, C. D. (1983) Manual for the State-Trant Anxiety Inventory: STAI-Form $Y$. Consulting Psychologists Press, Palo Alto, CA

Spielberger, C. D., Jacobs, G., Russell, S. et al. (1983) Assessment of anger: the state-trait anger scale. In Advances in Personality Assessment, eds. J. N. Butcher and C. D. Spielberger, Vol. 2, pp. 159-187. Erlbaum, Hillsdale, NJ.

Tempelaar, R., De Haes, J. C. J. M. and Van den Heuvel, W. J. A. et al. (1987) Een meetinstrument voor positieve en negatieve sociale ervaringen van (kanker)patiënten [A measurement instrument for positive and negative social experiences in (cancer)patients]. Tijdschrift voor Sociale Gezondheidszorg 65, 648-653.

Triemstra, A. H. M., Smit, C. and Van der Ploeg, H. M. et al. (1995) Two decades of haemophilia treatment in the Netherlands, 1972-1992. Haemophilia 1, 165-171.

Turner, J. A., Clancy, S. and Vitaliano, P. P. (1987) Relationships of stress, appraisal and coping, to chronic low back pain. Behavioural Research and Therapy (Special Issue: Chronic Pain) 25, 281-288.

Van der Ploeg, H. M. (1989) Zelfbeoordelings VragenlijstNijmegen (ZBV-N) [Self-Assessment QuestionnaireNijmegen $(S A Q-N)]$. Swets and Zeitlinger, Lisse, The Netherlands.

Van der Ploeg, H. M., Defares, P. B. and Spielberger, C D. (1980) Handleiding bij de Zelfbeoordelings Vragenlijst (Manual for the Dutch adaptation of the Self-assessment Questionnaire, STAI-Y). Swets and Zeitlinger, Lisse, The Netherlands.

Van der Ploeg, H. M., Defares, P. B. and Spielberger, C. D. (1982) Handleiding bij de Zelf-Analyse Vragenlijst (Manual for the Dutch adaptation of the STAS). Swets and Zeitlinger, Lisse, The Netherlands.

Van Oostrom, M. A., Tijhuis, M. A. R. and De Haes, J. C. J. M. et al. (1995) A measurement of social support in epidemiological research: the social experiences checklist tested in a general population in The Netherlands. Journal of Epidemiology and Community Health 49, 518524.

Verbrugge, L. M. and Jette, A. M. (1994) The disablement process. Social Science and Medicine 38, 1-14.

Wallston, K. A., Wallston, B. S. and DeVellis, R. (1978) Development of the multidimensional health locus of control (MHLC) scales. Health Education Monthly 6, 160-169.

Weinberger, M., Tierney, W. M. and Booher, P. et al. (1990) Social support, stress and functional status in patients with osteoarthritis. Social Science and Medicine 30, 503-508.

Wilson, I. B. and Cleary, P. D. (1995) Linking clinical variables with health-related quality of life. Journal of the American Medical Association 273, 59-65.

World Health Organization (1980) International Classification of Impairments, Disabilities and Handicaps A Manual of Classification relating to the Consequences of Disease. WHO, Geneva.

Zung, W. W. K. (1965) A self-rating depression scale. Archives of General Psychiatry 12, 63-70. 